11

\title{
Процесс кристаллизации при наличии течения
}

\author{
() Е.Д. Эйдельман ${ }^{1,2}$, М.А. Дурнев ${ }^{1}$ \\ ${ }^{1}$ Санкт-Петербургский государственный химико-фрармацевтический университет, \\ Санкт-Петербург, Россия \\ ${ }^{2}$ Физико-технический институт им. А.Ф. Иофффе РАН, \\ Санкт-Петербург, Россия \\ E-mail: Eidelman@mail.ioffe.ru
}

Поступила в Редакцию 16 июля 2019 г.

В окончательной редакции 16 июля 2019 г.

Принята к публикации 25 июля 2019 г.

\begin{abstract}
Предложен метод расчета распределения по размерам закритических зародышей при наличии течений в расплаве или паре для фазового перехода первого рода, а именно для кристаллизации или конденсации. Предложенный метод подтверждается сравнением с результатами экспериментальных исследований центробежного литья Al.
\end{abstract}

Ключевые слова: кристаллизация, зародышеобразование, $\mathrm{Al}$.

DOI: $10.21883 /$ FTT.2020.01.48727.28ks

\section{1. Введение}

В фазовом переходе первого рода выделяют две стадии. Первая $[1, \S 162]$ - образование в метастабильной системе зародышей критического размера, а именно такого размера, что система не возвращается в первоначальное однофазное состояние. Начальная стадия фазовых переходов первого рода общеизвестна. На этой стадии не имеет значения есть или нет в первичной фазе макроскопическое движение. Вторая стадия $[2, \S 99-102]$ - это развитие закритических „больших“ зародышей новой фазы. Именно такие быстрорастущие зародыши аккумулируют, присоединяют, поглощают метастабильную фазу с мелкими зародышами.

В настоящей работе внимание будет сосредоточено именно на второй стадии, причем, на примере кристаллизации. Теория этой стадии процесса нуклеации при отсутствии макроскопических течений в метастабильном материале хорошо известна, правда, такая теория строится на примере конденсации пара (см., например, обзор [3]). В самые последние годы в рамках такой теории найдено распределение закритических зародышей по размеру и его изменение с течением времени $[4,5]$. В этих работах теория строится для системы, в которой макроскопическое движение отсутствует.

В настоящей работе ставится задача найти распределение закритических зародышей при наличии течения. Такое распределение будет получено теоретически и подтверждено на примере исследования композита, полученного методом центробежного литья из алюминиевого сплава АК12 и частиц $\mathrm{Al}_{2} \mathrm{O}_{3}$ и $\mathrm{C}$ [6].

\section{2. Постановка задачи}

В [5] установлено, что на конечной стадии фазового перехода первого рода для закритических зародышей в отсутствие макроскопического движения за время $t$ устанавливается следующее распределение зародышей по их размеру $x$ :

$$
P(x)=\frac{B}{\sqrt{D t}} \exp \left(\frac{-x^{2}}{4 D t}\right) .
$$

Амплитудный параметр $B$ и диффузия зародышей с коэффициентом $D$ являются характеристиками конкретного фазового перехода.

Основная идея дальнейшего рассмотрения при наличии макроскопического движения в среде заключается в том, что движение на конечной стадии фазового перехода первого рода для закритических зародышей считается не диффузией, а перемешиванием. Такой переход имеет место, например, при превращении ламинарного течения в турбулентное [7]. Перемешивание определяется скоростью $v$ и длиной перемешивания. Из соображений размерности следует, что коэффициент диффузии заменяется величиной

$$
D=C v R
$$

где $R$ - усредненный размер растущих закритических зародышей; $C$ - безразмерный коэффициент порядка единицы.

\section{3. Решение задачи о распределении для центробежного литья}

В данном разделе будет рассмотрено влияние течения при фазовом переходе первого рода жидкость - твердое тело, создаваемого центростремительными силами и силой вязкого трения закритических зародышей именно на заключительной стадии кристаллизации, стадии коалесценции, когда рост крупных зародышей, имеющих 
плотность $\rho$, определяется поглощением мелких. При переходе из жидкой фазы при кристаллизации, в частности при центробежном литье, при вращении расплава с угловой скоростью $\omega$ необходимо учитывать макроскопическое движение малых зародышей в метастабильном состоянии - наличие течений на расстоянии $r$ от оси вращения.

Основными силами, действующими на растущий зародыш - образующуюся вокруг него область твердой фазы размером $R$, являются внешняя сила, далее будет рассматриваться центростремительная сила, и сила вязкого трения $6 \pi \eta R v$, если зародыш движется в расплаве с вязкостью $\eta$ со скоростью $v$. Далее зародыш считается шарообразным с радиксом $R$. Если зародыш расположен так, что твердую фазу вокруг нее нужно считать цилиндром, вытянутым по направлению центробежной силы, то сила вязкого трения будет в 2 раза меньше. Легко найти, что начальная скорость $\omega r$ затухает со временем $t$ по закону

$$
v=\frac{2}{9} \frac{\rho R^{2}}{\eta} \omega^{2} r-\omega r \exp \left(\frac{9 \eta}{2 \rho R^{2}} t\right) .
$$

Именно эта скорость заменяет среднеквадратичную скорость движения малых зародышей, которые поглощаются - соединяются - с большими в отсутствие течения. За время меньшее, чем характерное время затухания, именно эта скорость определяет вероятность поглощения большим - растущим, зародышем малых.

При наличии вращения нужно вместо коэффициента диффузии подставлять в (1) величину

$$
D=C R\left(\frac{2}{9} \frac{\rho R^{2}}{\eta} \omega^{2} r-\omega r \exp \left(\frac{-9 \eta}{2 \rho R^{2}} t\right)\right) .
$$

При сильном вращении центробежные силы способствуют росту преимущественно в направлении от оси вращения к изложнице. Отсюда следует, что размер зародыша $x$ становится равен расстоянию от первоначального положения зародыша до внешней границы расплава.

Для получения из (1) распределения $P$ зародышей непосредственно перед кристаллизацией в (1) нужно подставить время фазового перехода $t_{f}$, и подставить в (1) величину $D$, которая определяется течением в соответствии с формулой (4).

Запишем распределение - содержание, закритических зародышей перед фазовым переходом в зависимости от расстояния $x$, отсчитанного от внешней стенки образца или, что тоже самое при центробежном литье, от изложницы. Имеем,

$$
P(x)=A \exp \left(-\frac{x^{2}}{4 \sigma^{2}}\right),
$$

Здесь $A$ - амплитуда, максимальное значение функции распределения. Среднеквадратичное отклонение в рас- пределении имеет вид

$$
\sigma^{2}=D t_{f}=R\left(\frac{2}{9} \frac{\rho R^{2}}{\eta} \omega^{2} r-\omega r \exp \left(\frac{-9 \eta}{2 \rho R^{2}} t_{f}\right)\right) t_{f} .
$$

Величина $C$ из (2) включена в величину $t_{f}$, определенную наиболее грубо.

\section{4. Сравнение с экспериментом}

Для сравнения с развитой выше теорией удалось использовать результаты работ, изложенные в [6]. Эти работы посвящены созданию градиентных композиционных материалов (ГКМ) могут помочь в решении задач, возникающих при проектировании конструкций, предназначенных для работы в экстремальных условиях [8]. Перспективным методом получения ГКМ является центробежное литье, особенно для материалов на основе алюминия [6]. Для получения ГКМ кроме основного материала используются дополнительные материалы. ГКМ отличаются от традиционных изотропных композитных материалов наличием пространственно-неоднородных структур дополнительных материалов, благодаря которым они приобретают новые свойства и новые функции. Для сравнения с теорией важно, что частицы дополнительного материала после кристаллизации видны под микроскопом и их можно рассматривать как зародыши в состоянии расплава в закритической области перед кристаллизацией. Это позволяет проводить определение распределения зародышей в закритической области по данным о положении частиц дополнительного материала после кристаллизации с помощью микроскопа (рис. 1).

Сравнение теории с экспериментом проводилось на образцах (см. [6]), в которых в качестве основного материала использовался сплав АК12, имеющий в жидком состоянии плотность $\rho_{\mathrm{Al}} \approx 2.67 \mathrm{~g} / \mathrm{cm}^{3}$. В качестве дополнительных материалов использовались частицы оксида алюминия $\mathrm{Al}_{2} \mathrm{O}_{3}$ со средним наибольшим размером $40 \mu \mathrm{m}$, имеющие плотность $\rho_{\mathrm{Al}_{2} \mathrm{O}_{3}}=4.00 \mathrm{~g} / \mathrm{cm}^{3}$, и графит $\mathrm{C}$ со средним наибольшим размером $400 \mu \mathrm{m}$ и плотностью $\rho_{\mathrm{C}}=1.70 \mathrm{~g} / \mathrm{cm}^{3}$. Использование для сравнения с теорией результатов полученных для образцов с совместным введением двух добавок связано с тем, что $\rho_{\mathrm{Al}_{2} \mathrm{O}_{3}}>\rho_{\mathrm{Al}}$, а $\rho_{\mathrm{C}}<\rho_{\mathrm{Al}}$. Для образцов с другими типами дополнительного материала результаты аналогичны [9-11]. Образцы изготавливались в одинаковых условиях с температурой оснастки $T=210 \pm 10^{\circ} \mathrm{C}$ и температурой расплава $T=750 \pm 10^{\circ} \mathrm{C}$ методом центробежного литья при угловой скорости $\omega=40 \pi \mathrm{rad} / \mathrm{s}$ и имели форму полых цилиндров с расстоянием $r$ до оси $\sim 60 \mathrm{~mm} \leq r \leq 92-94 \mathrm{~mm}$ и высотой 60-90 $\mathrm{mm}$. Разрезанные на сектора цилиндры исследовались на микроскопе Leica c наружной и внутренней стороны боковой поверхности. Типичный результат микроскопического исследования, подготовленный для проведения сравнения с функцией распределения, представлен на рис. 1. 


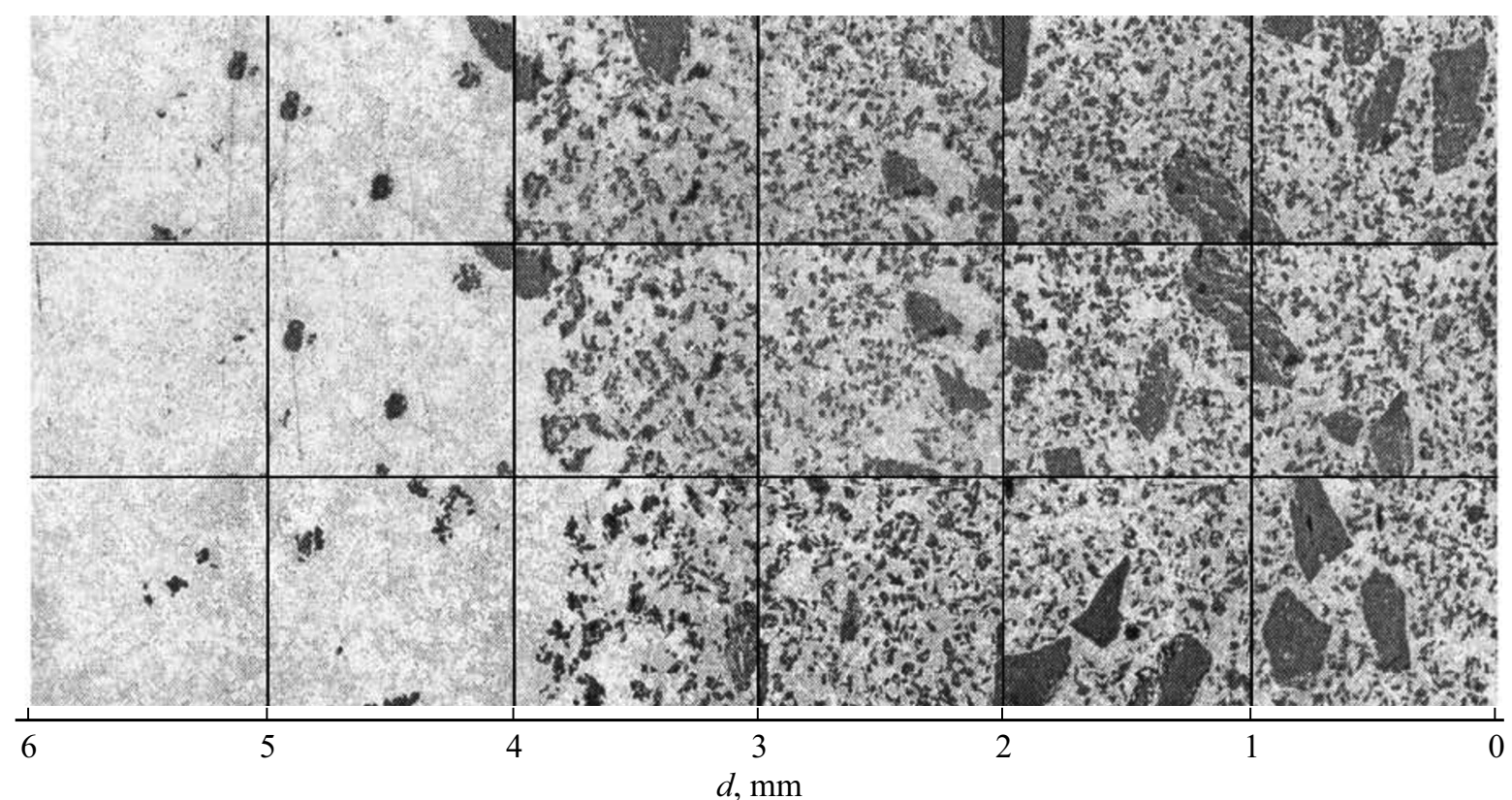

Рис. 1. Микроструктура образцов $\mathrm{AK} 12+10 \% \mathrm{Al}_{2} \mathrm{O}_{3}+2 \% \mathrm{C}$ после кристаллизации. Темные области - дополнительный материал. Частицы С имеют средний наибольший размер $400 \mu \mathrm{m}$, а частицы $\mathrm{Al}_{2} \mathrm{O}_{3}-40 \mu \mathrm{m}$. Справа налево отложено расстояние $d$ от наружной стенки в миллиметрах.

В каждой клетке подсчитывалась доля зародышей частиц дополнительного материала. Эта доля в зависимости от расстояния $d$ от наружной стенки представлена

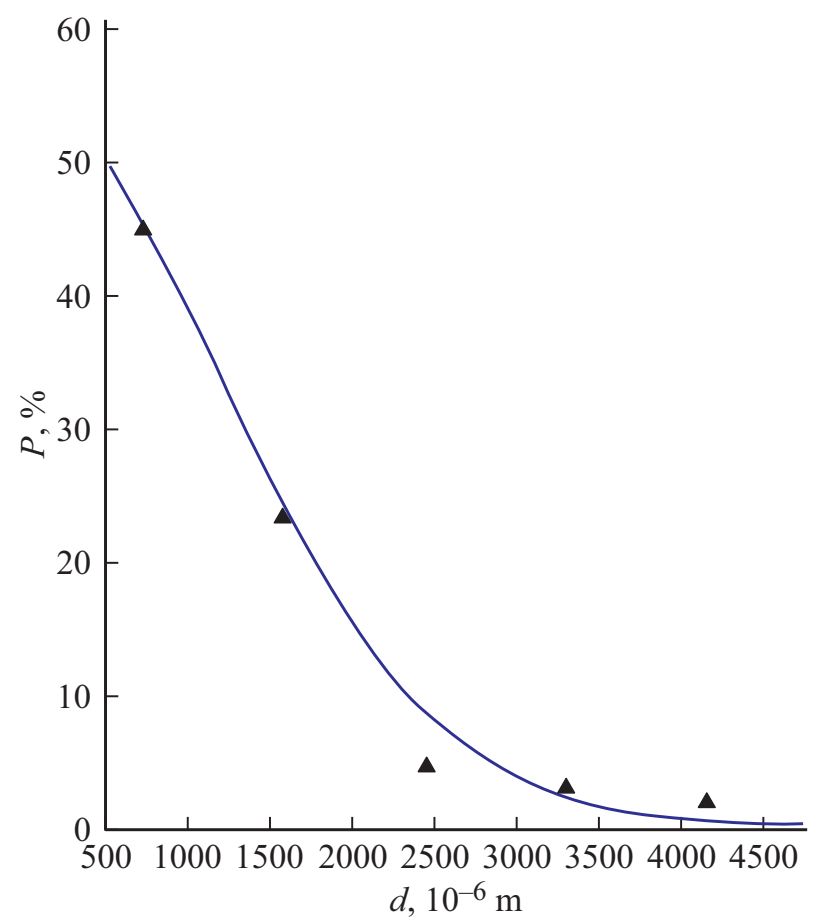

Рис. 2. Распределение армирующих примесей - зародышей - в средней части образца, которая показана на рис. 1. Гауссова кривая проведена методом наименьших квадратов отклонений от экспериментальных значений. Полуширина $\sigma=3.6 \mathrm{~mm}$. точками на рис. 2. В качестве примера использована средняя часть образца, микроскопическое исследование которого представлено на рис. 1. Сплошная линия гауссова кривая - проведена методом наименьшего квадрата отклонения. Максимальное значение составляет $50 \%$, а полуширина $\sigma_{e x}=3.6 \pm 0.4 \mathrm{~mm}$.

Полученная таким образом кривая представляет собой найденное из эксперимента распределение зародышей в закритической области. Это распределение будем сравнивать с распределением (5), полученным теоретически. Кристаллизация $[4,5]$ происходит в основном на центрах конденсации, образующихся вокруг частиц дополнительного материала.

Главное предположение, то есть наиболее грубое допущение, которое при этом будет сделано, состоит в том, что при центробежном литье зародыши под действием центростремительной силы при достаточно быстром вращении растут, в основном, именно в радиальном направлении. Поэтому в закритической области можно считать, что размер зародыша $x$ совпадает с расстоянием от частицы дополнительного материала, из которого начинает формироваться зародыш, до внешней границы - до изложницы $d$. Итак, главное предположение сводится к следующему равенству

$$
x \approx d \text {. }
$$

Коэффициент вязкости в АК12 в расплавленном состоянии $\eta \approx 0.32 \mathrm{~Pa} \cdot \mathrm{s} ; v_{i}$ и $R_{i}-$ соответственно, скорость и размер закритического зародыша $\mathrm{Al}_{2} \mathrm{O}_{3}(i=1)$ и частицы графита $\mathrm{C}(i=2)$. В соответствии с данными, приведенными выше, $R_{1}=20 \mu \mathrm{m}, R_{2}=100-200 \mu \mathrm{m}$. 
Скорость каждого сорта частиц имеет тот же вид (3), но для частиц соответствующего дополнительного материала. Соответственно в коэффициенте диффузии (2) будет два слагаемых. Запишем,

$$
D=D_{1}+D_{2}=C_{1} n_{1} v_{1} R_{1}+C_{2} n_{2} v_{2} R_{2} .
$$

Величина $n_{i}$ - численная доля большого зародыша соответствующего сорта. Очевидно, что $n_{1} \gg n_{2}$ и поэтому $D_{1} \gg D_{2}$.

Искомое распределение (5) также состоит из двух слагаемых

$$
P(x)=A_{1} \exp \left(\frac{-x^{2}}{4 \sigma_{1}^{2}}\right)+A_{2} \exp \left(\frac{-x^{2}}{4 \sigma_{2}^{2}}\right) .
$$

Параметры $A_{i}$ обусловливают максимальное значение функции распределения, а само максимальное значение определяется концентрацией дополнительного материала, которая, в свою очередь, определяется седиментацией под действием разности силы тяжести и силы Архимеда - силы плавучести. Из-за того, что плотность графитовых частиц гораздо меньше плотности частиц оксида алюминия, выполняется неравенство $A_{1}>A_{2}$. Отметим, что определение максимального значения функции распределения не является целью настоящей работы (см., впрочем, [10] и [11]).

Среднеквадратичные отклонения - полуширина - в распределении имеют вид

$$
\sigma_{i}^{2}=D_{i} t_{f}=R_{i}\left(\frac{2}{9} \frac{\rho_{i} R_{1}^{2}}{\eta} \omega^{2} r-\left(\frac{-9 \eta}{1 \rho_{i} R_{i}^{2}} t_{f}\right)\right) .
$$

Величины $C_{i}$ из (10) включены в величину $t_{f}$, определенную наиболее грубо.

Важно, что среднеквадратичные отклонения не зависят от сил плавучести. Оказалось, что среднеквадратичные отклонения, вычисленные по формуле (10), составляют $\sigma_{\text {theor }} \approx 2-4 \mathrm{~mm}$ при времени кристаллизации - времени фазового перехода $-t_{f}$ порядка $3-10 \mathrm{~s}$. Например, $\sigma_{\text {theor }}=\sigma_{e x}=3.6 \mathrm{~mm}$ при $t_{f}=7.8 \mathrm{~s}$.

\section{5. Заключение}

Известно, что с помощью подбора дополнительных армирующих материалов, имеющих плотности больше и меньше, чем основной материал, можно создавать ГКМ с заданной твердостью методом центробежного литья. Необходимые количества дополнительных материалов могут определяться по их распределению на заключительной стадии кристаллизации, распределению зародышей в закритической области фазового перехода. Этот практический вывод основан на рассмотрении модели действия центробежной силы и предсказаний по распределению армирующих материалов.

С точки зрения теории развитый в данной работе метод открывает путь определения длительности времени, фазового перехода: расплав - поликристаллическая структура, по экспериментальным данным о распределении зародышей.

\section{Благодарности}

Благодарим М.Л. Хейфеца, обратившего наше внимание на проблемы, связанные с получением ГМК методом центробежного литья.

\section{Конфликт интересов}

Авторы подтверждают, что у них нет конфликта интересов.

\section{Список литературы}

[1] Л.Д. Ландау, Е.М. Лифшиц. Статистическая физика. Часть 1. Физматлит, М. (2004). Т. 5. 584 с.

[2] Е.М. Лифшиц, Л.П. Питаевский. Физматлит, М. (2004). T. $10.536 \mathrm{c}$.

[3] А.М. Куни, А.К. Щекин, А.П. Гранин. УФН 171, 345 (2001).

[4] V.B. Kurasov. Advances in the first order phase transitions. II. St.-Petersburg.: VVM Publishing Ltd. (2013). 319 pp.

[5] В.Б. Курасов. Письма в ЖТФ 41, 7, 89 (2015).

[6] П.А. Витязь, М.Л. Хейфец, В.Т. Сенють, А.Г. Колмаков, Ю.С. Алексеева, Л.И. Кобелева, И.Е. Калашников. Прогрессивные технологии и системы машиностроения 3 (54), 18 (2016).

[7] Л.Д. Ландау, Е.М. Лифшиц. Гидродинамика. Физматлит, М. (2004). T. 6. $584 \mathrm{c}$.

[8] М.Л. Хейфец. Проектирование процессов комбинированной обработки. Машиностроение, М. (2005). 272 с.

[9] M.A. Durnev, E.D. Eidelman. Nanosystems: Physics, Chemistry, Mathematics. 8, 3, 360 (2017).

[10] Е.Д. Эйдельман, М.А. Дурнев. ЖТФ 88, 11, 1667 (2018). DOI: 10.21883/JTF.2018.11.46627.2531.

[11] Е.Д. Эйдельман, М.А. Дурнев. Письма в ЖТФ 44, 7, 23 (2018). DOI: 10.21883/PJTF.07.45881.16902.

Редактор Ю.Э. Китаев 